\section{THE TREATMENT OF DEFORMITIES OF THE SPINE CAUSED BY POLIOMYELITIS}

A REPORT OF EIGHT CASES IN WHICH FUSION OPERATIONS WERE PERFORMED *

RUSSELL A. HIBBS, M.D.

NEW YORK

Deformities which develop in consequence of permanent damage to the muscles of the spine from anterior poliomyelitis are among the most difficult with which the orthopedic surgeon has to deal, and I know of no means which can be depended on to prevent their progress. Plaster jackets and braces can, at best, only retard the development of deformity.

It has seemed to me practical, therefore, in such cases, to do a fusion operation on the spine exactly similar to that which has been used in the treatment of Pott's disease at the Orthopaedic Hospital since 1910.

It is my purpose to report eight cases in which this operation has been done for scoliosis. None of these patients were operated on until long after the acute attack, and obviously one would not operate at all if there were any prospect of recovery of the muscles affected. I do not think, however, it is at all necessary to wait as long as we have waited in these cases.

This operation is in every essential feature precisely the same as that performed on patients with Pott's disease. Since there seems to have been some misunderstanding of the technic of the operation, perhaps a description of it here will not be out of place.

An incision is made directly over the spinous processes through skin, subcutaneous tissue and ligament to the tips of the spinous processes. The periosteum over each tip and the ligament between is split. The periosteum is then elevated from the bone over a part of each process in turn. As the periosteum is separated from the bone, small packings of gauze are made to prevent ooz ing. Separation of the periosteum is carried forward gradually until each spinous process

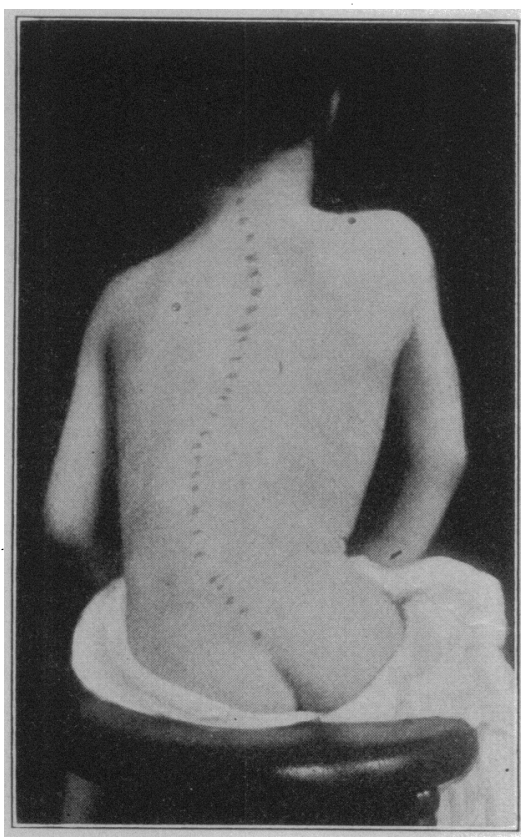

Fig. 1 (Case 1).-Condition before operation. and lamina is com-

pletely bare to the base of the transverse process. This is done in children with a blunt periosteal elevator and in adults with a sharp one, as in the latter the periosteum is more adherent.

- Read before the Section on Orthopedic Surgery at the Sixty-Eighth Annual Session of the American Medical Association, New York June, 1917.
The periosteum is then pushed from the adjacent bases of the spinous processes and the adjacent edges of the laminae to the ventral side with a small curet or a periosteal elevator. With this dissection made, the operative field is ready for any treatment of the exposed bone that is desirable. The first thing to be done is to curet the lateral articulations which lie at the base of the transverse process and are alway s a sily reached in children and in most adults. After this is accomplished, a small piece of bone is elevated from the laminae and turned down, its free end resting on the one next below it. The spinous processes are then partially divided, with forceps for that purpose, and broken down so that the tip of one comes in contact with the base next below it. This completes all that is necessary to do to the bone.

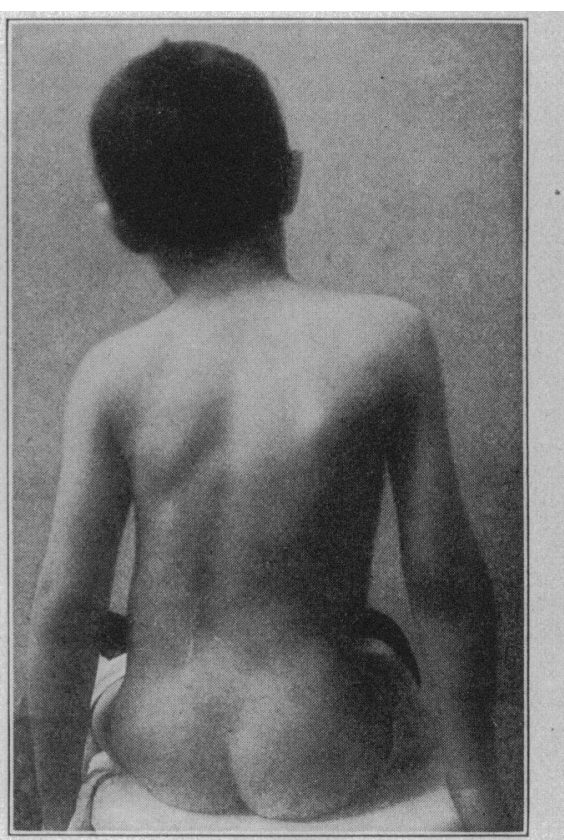

Fig. 2 (Case 1).-Condition after opera. tion.
The periosteum and ligament which have been separated are then brought together and sutured in the center with interrupted ten day chromic catgut. The skin wound is closed with continuous ten day chromic catgut. Dressings and brace or jacket are applied.

The importance of cureting the lateral articulation is evident, as it insures a fusion of bone at that point. Turning a piece of bone down from one lamina across to the next below prevents any tissue from falling between the laminae, thus insuring their fusion, while the importance of the transposition of the spinous processes is obvious. With the closure of the periosteum in the center, we have practically a periosteal tube filled with fresh, healthy, bleeding bone in uninterrupted contact from one end of the operative field to the other, insuring a fusion of the lateral articulations, laminae and spinous processes.

Immediately after operation a brace or jacket is applied, maintaining as much correction as is comfortable to the patient. $\mathrm{My}$ own preference is a steel brace which has already been made and fitted before operation. The patient is kept in bed for eight weeks, and the brace is worn for one year.

In six of these cases there was conspicuous deformity, and such weakness in three, that the patients could not sit up unaided, much less walk. All of them have been given a much better posture, much more stability, and, it is believed, protection from a progressive increase of deformity and probably have been saved from the necessity of wearing a brace or jacket for indefinite periods.

I can see no possible disadvantage in fusing even longer segments of the spine than in these cases; in fact, I think in some it would have been better to make 
a longer fusion. If, as seems probable, such an operation can prevent these conspicuous deformities, it should be done in many of these cases and earlier, before such irreparable damage has taken place.

\section{REPORT OF CASES}

CASE 1.-H. H., boy, aged 6, who had infantile paralysis at 11 months, was admitted to the hospital, June 20, 1914. There was loss of power in all muscles of the right thigh and leg; there was some power in the external rotators, abductors and external hamstring of the left leg, but very slight power in the calf and long flexors; there was complete loss of power

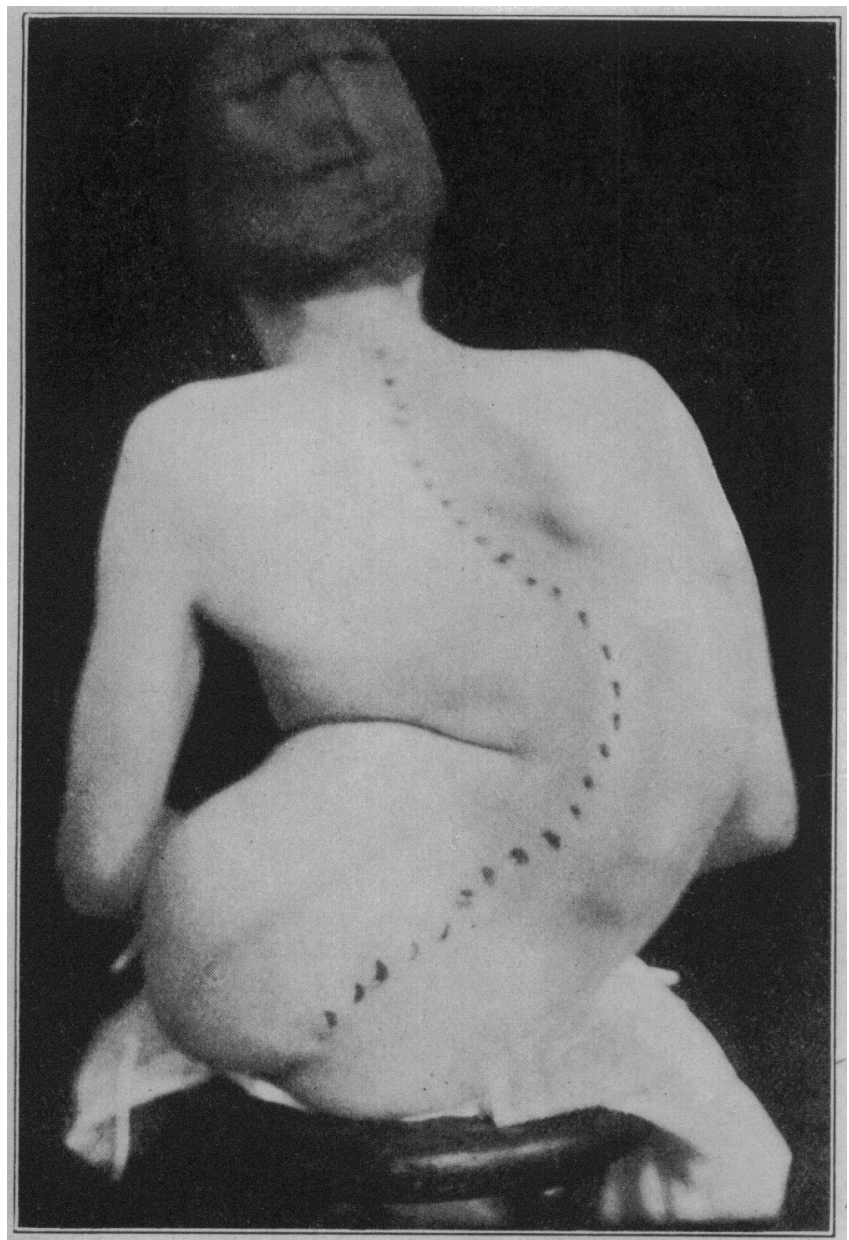

Fig. 3 (Case 2).-Fosition assumed by patient on attempting to sit.

in all the other muscles. Muscles in the right lumbar region of the spine were extensively involved, and there was a marked dorsolumbar curve to the right with marked rotation; the patient was unable to sit up at all without support. At the operation, June 23, 1914, a fusion was done from the tenth dorsal to the fourth lumbar vertebrae, both inclusive. The wound healed without complication, and there has taken place a fusion throughout the operative field, preventing any increase in deformity and increasing the stability of the spine so that sitting unaided is possible. Support was worn for one year afterward, and with braces applied to legs the patient is able to walk, Figure 1 shows the patient before operation and Figure 2 after operation.

CASE 2.-J. K., girl, aged 14, entered the hospital, April 27, 1915. She had infantile paralysis at $3 \frac{1}{2}$ years of age, both legs being extensively involved with conspicuous deformities and extensive involvement of the spine, permitting a right dorsolumbar curve with marked rotation. She had never been able to walk or sit up since paralysis. Figure 3 shows the position assumed by the patient on attempting to sit; even this was not possible without holding herself up by her hands. After correction of the leg deformities, a spine fusion was done, Nov. 3, 1915, extending from the eleventh dorsal to the fourth lumbar vertebrae, inclusive. Fusion is complete throughout the operative field, and she has capacity

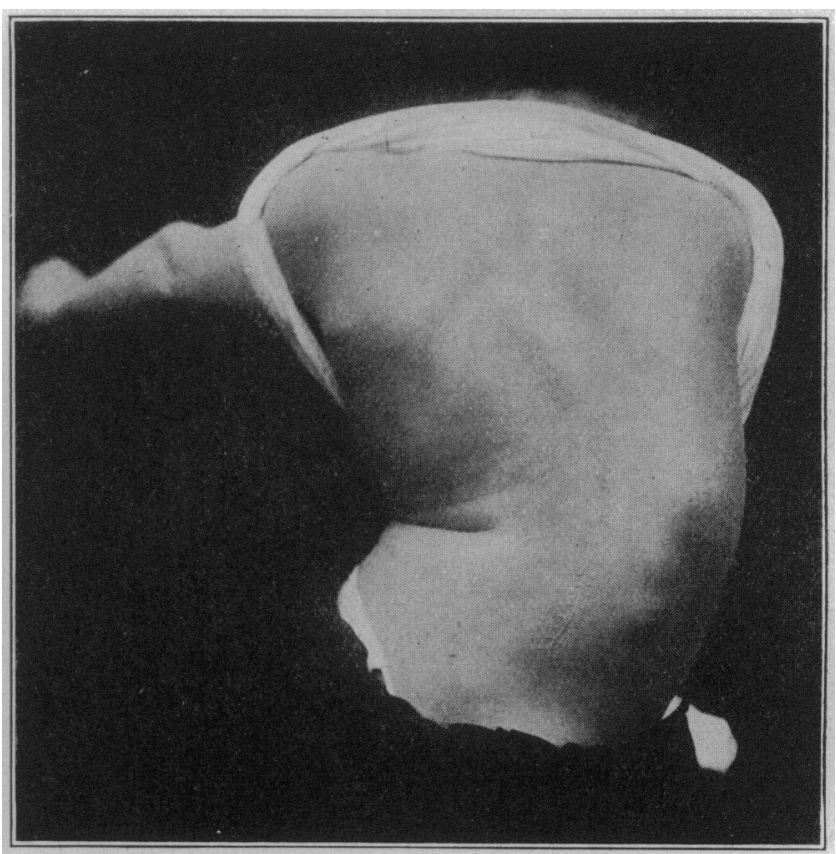

Fig. 4 (Case 2),-... Condition one year after operation.

now to sit up without assistance and, while I do not believe a sufficient number of vertebrae were included in this case, at the same time the patient is immensely improved. Figure 4 was taken one year after operation; with braces on her legs, the patient is able to walk. She still wears a light steel support to her spine.

CASE 3.-C. R., boy, aged 14 , had infantile paralysis at the age of 5 , with, extensive involvement of both legs and the spine and a dorsolumbar curve with convexity to the right and with marked rotation. January 19, a fusion operation was done from the ninth dorsal to the third lumbar, inclusive. Fusion is complete, progress of deformity stopped, and the stability of the spine much improved. Figure 5 was taken after operation. Photograph before operation was not obtainable.

CASE 4.-W. D., boy, aged 6 , had infantile paralysis at 2 years of age, with extensive paralysis of both legs.

The spinal group of

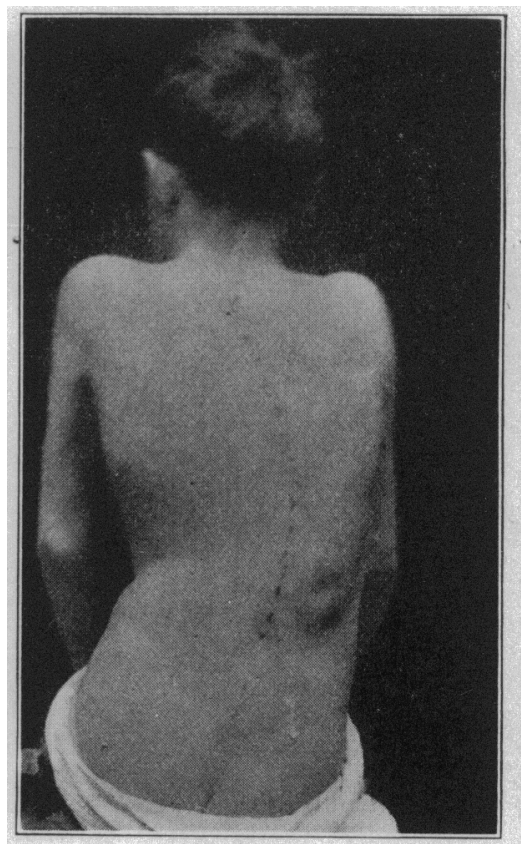

Fig. 5 (Case 3).-Condition after oper:Fi
tion.

marked dorsolumbar curve to the right with rotation. The patient was admitted to the hospital, May 1, 1916. Fusion operation from the eighth dorsal to the third lumbar vertebrae, inclusive, was performed, May 19, 1916. Complete fusion was secured, with marked improvement; no progress of deformity 
was detected. Figures 6 and 7 show the condition before and after operation. infantile paralysis at 4 years, leaving extensive paralysis of both legs and the spine. The patient never had walked or
CASE 5.-S. S., boy, aged $6 \frac{1 / 2}{2}$ years, had an attack of

right with marked rotation. Spinal fusion from the seventh dorsal to the fourth lumbar was performed, July 18, 1916 Complete fusion was obtained and improvement was marked. Figures 12 and 13 show the condition before and after operation, respectively.

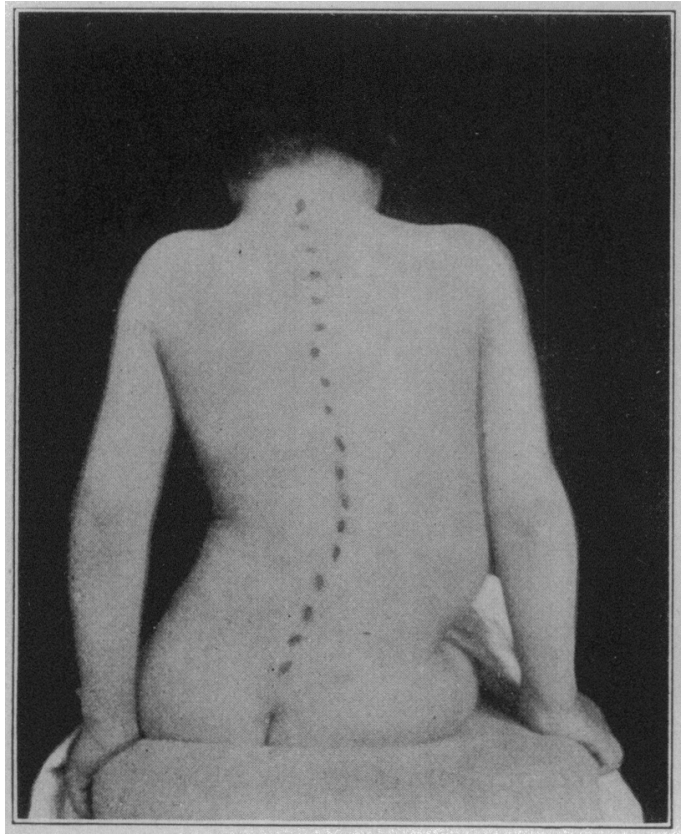

Fig. 6 (Case 4).-Condition before operation.

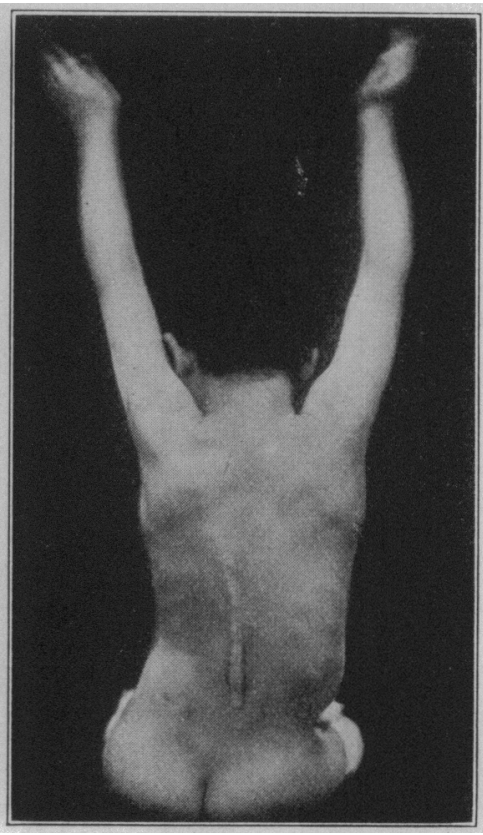

Fig. 7 (Case 4).-Condition after oper

CAse 8.-W. B., boy, aged 16 , had infantile paralysis at 2 years of age. The right quadriceps, left anterior tibial and peroneal groups of muscles were affected, and also the right spinal group, permitting a right dorsolumbar curvature with marked rotation. Spine fusion was performed, Dec. 29, 1916, including the eighth dorsal to third lumbar. Fusion was complete and improvement in both positions and stability of spine resulted. Figures 14 and 15 show the condition before and after operation, respectively.

130 East Thirty-Sixth Street.

\section{ABSTRACT OF \\ DISCUSSION}

Dr. Emil S. Geist, Minneapolis : How many vertebrae should be fixed?

Dr. Fred J. Fassett, Seattle: I think we all agree with Dr. Hibbs that it is bad for a patient to wear a body support longer than is necessary. We could go further and say that is difficult to find any form of body support which in

been able to sit up. The position when the patient attempted to sit up is shown in Figure 8 , taken before operation. Deformities of the legs were corrected and a spine fusion done, July 6,1916 , from the sixth dorsal to the third lumbar. While there has been marked improvement, evidenced by the fact that the patient can now sit without support, and with braces on his legs is able to walk, it is possible that a more extensive fusion might have been better. However, there can be no question that progress of the deformity has been checked, and improvement is marked. In such a case, of course, operation should have been performed long before s uch conspicuous deformity developed. Figure 9 was taken after operation.

CASE 6.-J. D., boy, aged 16 , had infantile paralysis at 1 year with complete paralysis of one leg, with the left spinal group affected, permitting a marked dorsolumbar curve to the left with rotation. The patient was unable to sit without assistance. Spine fusion was performed, Dec. 13, 1916, from the tenth dorsal to the third lumbar. Marked improvement in both position and stability of spine followed. In this patient, also, a spinal

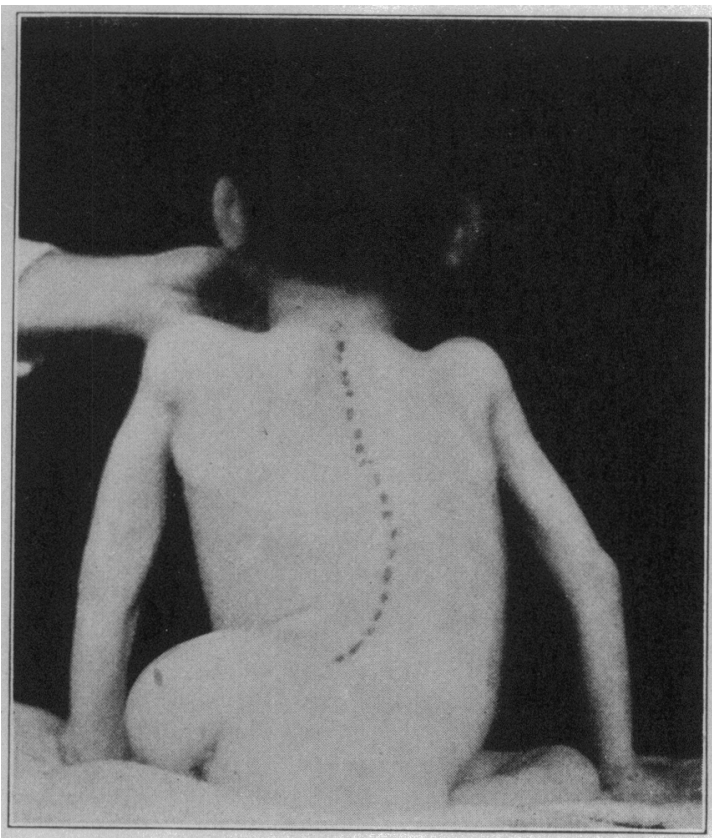

Fig. 8 (Case 5).-Position assumed by patient on attempting a paralytic scoliosis, will do the work. I have done only the bone splinting operation. In such cases, even where the splint has firmly healed in place, it has not had the slightest effect on the curvature or the rotation. If any operation would control a paralytic scoliosis it would be one which fusion should have been done earlier in life. Figures 10 and 11 show the condition before and after operation, respectively.

CASE 7.-F. D., boy, aged 9, had infantile paralysis at 4 years, leaving an extensive paralysis of the right leg and right spinal group, permitting a dorsolumbar curve to the

produced a perfect mass of new bone about the processes. This is what the operation used by Dr. Hibbs appears to do.

Dr. JoHn Ridlon, Chicago: I should like to have Dr. Hibbs say, if he will, why he did not make an effort to correct these spines before doing the fixative operation. These 
spines can be considerably, and sometimes completely, corrected; but the problem is to hold them in the corrected position. His operation would seem to be the way of holding them there; but why not do the other thing first? a substantial human tissue splint, and will in a way serve as a means of holding the trunk erect. If scar tissue will produce scoliosis, it is only fair to make it serve as a means of correcting it.

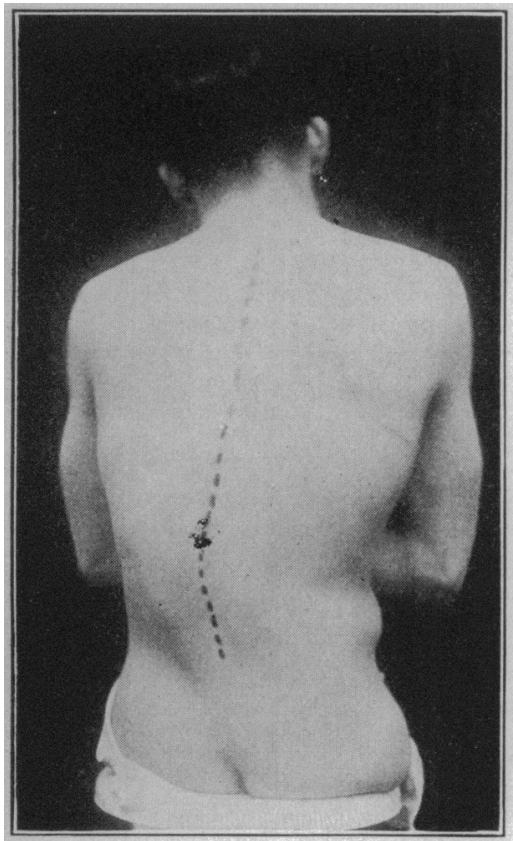

Fig. 10 (Case 6).-Condition before oper-

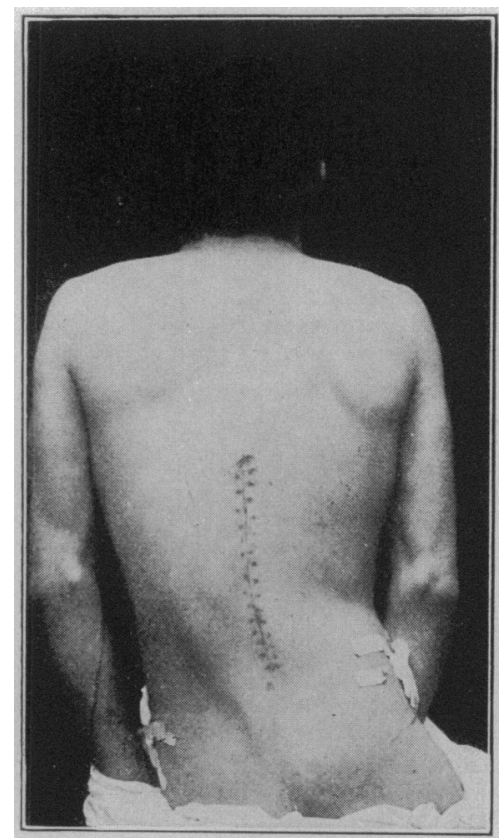

Fig. 11 (Case 6).-Condition after operation.

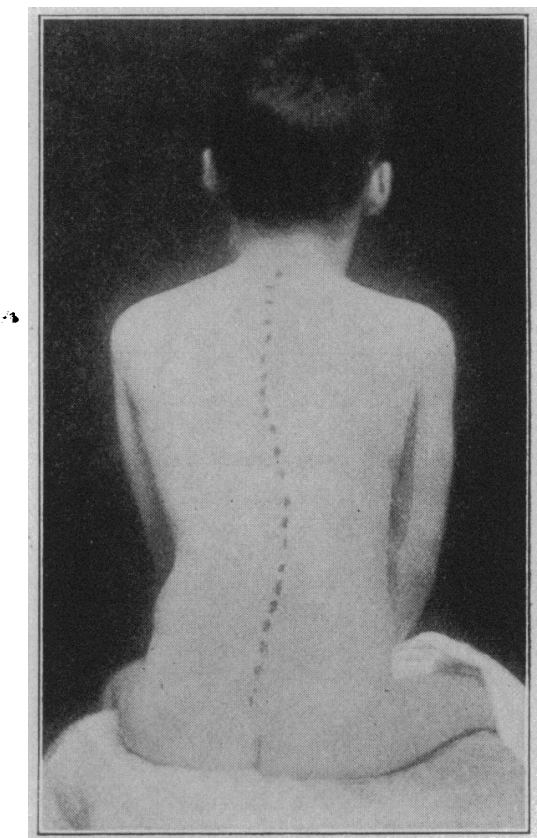

Fig. 12 (Case 7).-Condition before oper-
Dr. Horace R. Allen, Indianapolis: From time to time there come into our practice children and adults with horrible scolioses due to injury. I have had cases in which the patient had been burned, and the resulting cicatricial tissue would pull them over, and when the scar tissue was deep there was almost no way to get them straightened. I should
Dr. John Ridon, Chicago: Some scar tissue stretches instead of contracting, and it is not very good procedure to try to straighten a scoliotic spine by putting scar tissue on the convex side.

Dr. Albert H. Freiberg, Cincinnati: I commend what seems to me an excellently conceived procedure for these

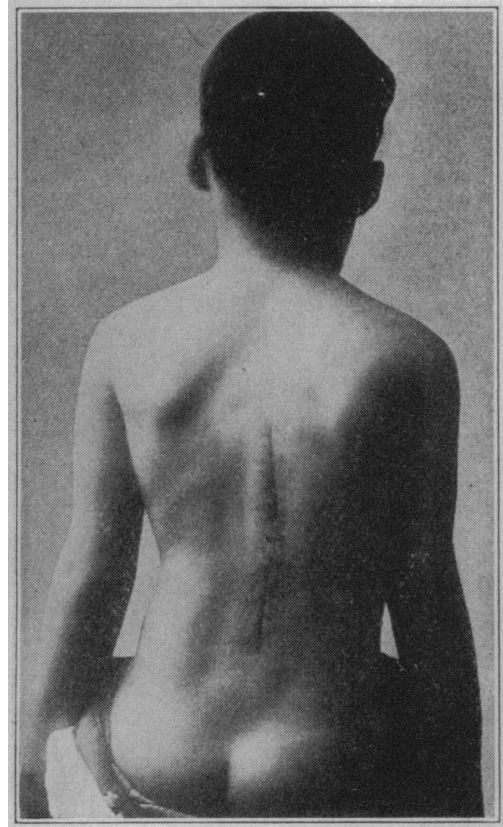

Fig. 13 (Case 7),-Condition after oper-

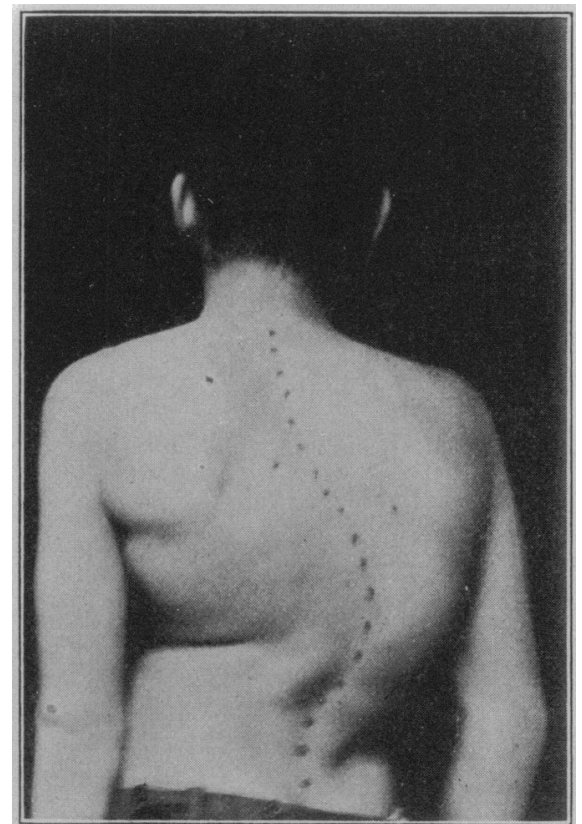

Fig. 14 (Case 8).-Condition before operation.

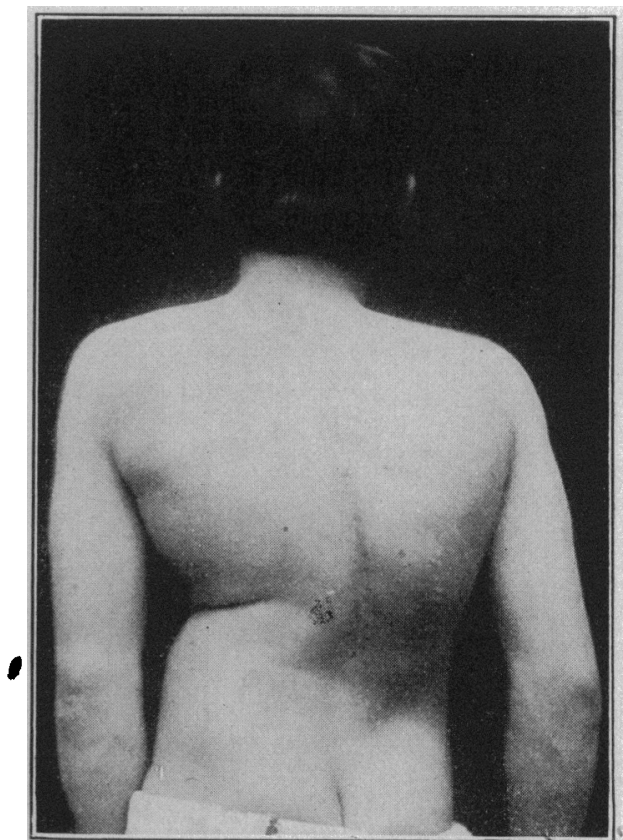

Fig. 15 (Case 8).-Condition after operation. like Dr. Hibbs to say whether he thinks the artificial production of scar tissue on the convex side might not be of benefit by contracting and holding the spine straight. Scar tissue is inelastic, as every one knows, and if it is deep enough and properly located it will be strong enough to serve as cases, and it seems to me, also, that it would be no mistake to operate in th se cases eurlier than has been done. I would regard this as the one exception that I might be willing to make to operating on paralytic deformities early. Whatever we may feel with regard to the relative merits of the bone 
grafting operation and the operation of Dr. Hibbs for Pott's disease, it seems to me that this would be the operation of choice for paralytic scoliosis, because it attacks the deformity at the periphery of the curve, which is supposed to be the chief point of merit in any fusing operation for Pott's disease. There is a large question that Dr. Hibbs will have to decide for us, and that is whether the correction he obtains will endure. It seems to me that there is abundant reason to doubt that, since there is inequality of muscular action, which will persist, presumably, as long as the child lives. It is a question whether the response to muscular pull on one side, and absence of it on the other, will not eventually cause a yielding of the vertebrae and an increase of the deformity.

Dr. E. D. Ebright, Wichita, Kan.: For the class of cases shown, I think Dr. Hibbs' operation is a most important. advance. Since last fall I have seen forty-two of these scolioses that, if they had been allowed to go on, would have become exactly the type of case represented by the worst picture shown by Dr. Hibbs. I think the necessity to do that operation, however, is a reproach to the medical profession, for these deformities can be prevented if the disease is taken in time and properly treated. As Dr. Freiberg says, the paralyses are equal on both sides, and the back is as liable to slump one way as the other. The fusion operation is much preferable to the splinting operation, which controls the spine in flexion and extension only, while this method stops side bending as well.

Dr. WALTER TRUSLOW, Brooklyn: We have watched these cases this summer and have prevented the deformity, and we have seen the strength slowly come back under protection and carefully guided muscle training. Of course,. we cannot yet know the ultimate result.

Dr. James W. Sever, Boston: It is not a question of muscle training over a period of a year; it is a question of holding the corrected position in these cases by adequate apparatus over a period of ten or fifteen years. If one talks of holding them for six months or a year only, one has not the correct conception to base results on.

I was glad to hear what Dr. Ebright said, but I think that he is an optomist, especially with regard to correction of scoliosis due to infantile paralysis. If he knows of any method to prevent its increasing in infantile paralysis I should like to know it.

DR. Russell A. HibBs, New York: The question asked by Dr. Geist, as to how many vertebrae to fuse, I would answer by saying that it depends on the extent of the curve. In some it was only necessary to fuse five or six; and in others, as many as twelve, depending on the extent of the curve and the amount of paralysis. No one would contemplate doing the fusive operation on a child whose spine was only temporarily affected. We wait and see the amount of permanent damage done by the infection.

In answer to Dr. Freiberg's question as to the permanency of the correction of these deformities, I would say that a longer time must elapse before a definite answer can be given. My own feeling is that it may be permanent.

In answer to Dr. Ridlon's question as to whether corrective work is done before operation, it is, and should always be I feel, however, that if a longer experience proves that a fusion operation will permanently prevent these deformities, it should be done earlier.

Imports of Senna.-Only since the beginning of the war has senna become an article of export from Aden to the United States, according to Consul Addison E. Southard, at Aden (Commerce Reports, July 2, 1917). The first shipments were made in the second quarter of 1916 and amounted to 31,273 pounds. Smaller shipments were made during the third quarter of the year. In the second quarter of 1917 the shipments amounted to 82,868 pounds, valued at $\$ 42,407$, ranking second in value of articles exported to the United States from Aden. The crude drug comes to Aden from the Yemen and other Red Sea Arabian provinces and the poorer grades from Abyśsinia and French Somaliland. At Aden it is cleaned before export, Indian women being employed to pick it over and throw out twigs, discolored leaves, etc.
REPORT OF AN OUTBREAK OF DIPHTHERIC WOUND INFECTION AMONG RETURNED SOLDIERS

J. G. FITZGERALD, M.B.

Major, Canadian Army Medical Corps; Associate Professor of Hygiene, University of Toronto, Faculty of Medicine

AND

D. E. ROBERTSON, M.B.

Major, Canadian Army Medical Corps; Assistant in Surgery, University of Toronto, Faculty of Medicine

TORONTO

We have been unable to find, in the literature accessible to us, references to epidemic outbreaks of wound infection due to Bacillus diphtheriae. The cases which have come under our observation during the past six weeks have therefore been of considerable interest.

For some months, wounded men of the Canadian Expeditionary Force on whom amputations of arms or legs or both were necessary have been returned to Toronto for further orthopedic treatment. Such patients were under the care of the Military Hospitals

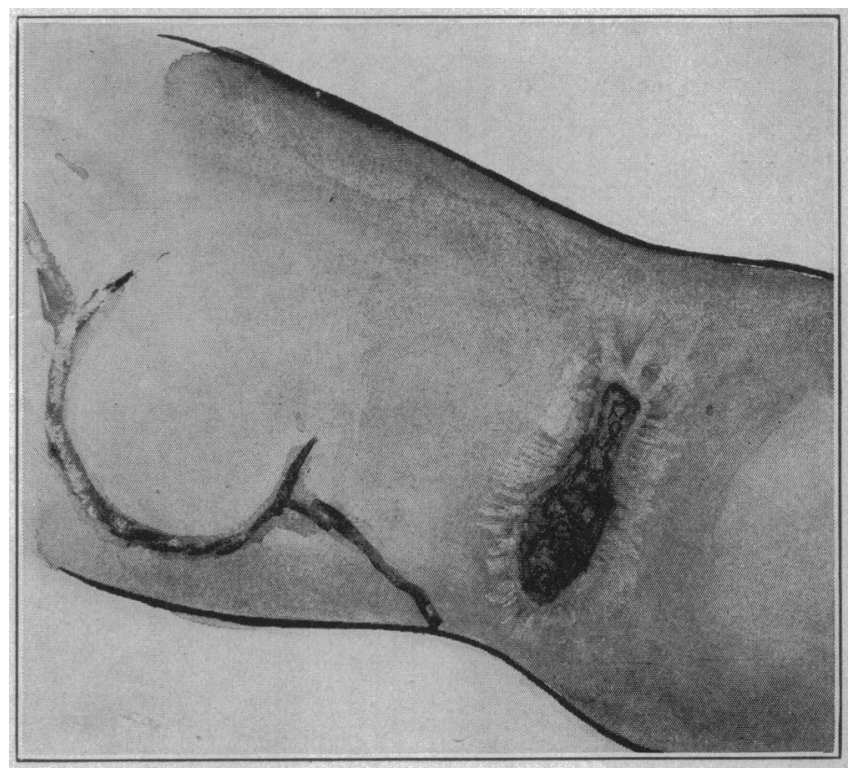

Fig. 1.-Diphtheric infection of inner side of left leg. The sinus is sunk (all around outside edge) below the normal level of the skin. edge. Swelling is prominent

Commission Command, "D" Unit, to which one of us (D. E. R.) is attached for duty.

During the first week in May, 1917, as a result of a thorough examination of suppurating stump wounds, one or two cases were observed which strongly suggested diphtheric infection. One of us (D. E. R.) made a clinical diagnosis of skin diphtheria, ordered a bacteriologic examination, had the man isolated, and diphtheria antitoxin was administered.

May 19,1917, this man (who belonged to an infantry battalion) was admitted to the isolation department of the military base hospital, Toronto, suffering from a diphtheric infection of a leg stump. The patient had a reamputation of the leg, March 31, 1917. For some time his stump did very well. About May 11 his stump showed signs of infection, and a bacteriologic examination revealed that the infection was due to $B$. diphtheriae. As soon as the patient was admitted to the base hospital, one of us (J. G. F.) as Sanitary Officer No. 2 in Military District No. 2, 